\title{
Pelatihan Kondisi Fisik Atlet Padepokan Judo Kesatria
}

\author{
Ahmad Muchlisin Natas Pasaribu ${ }^{1, *}$ \\ ${ }^{1}$ Fakultas IImu Pendidikan; Jl. Raya Perjuangan, Marga Mulya, Bekasi Utara, Kota Bekasi, \\ Jawa Barat 17121, Telp: (021) 88955882, 889955883; e-mail: \\ ahmad.muchlisin@dsn.ubharajaya.ac.id
}

* Korespondensi: e-mail: ahmad.muchlisin@dsn.ubharajaya.ac.id

\begin{abstract}
The purpose of this Community Service activity is to provide physical condition training to novice athletes, training programs for physical trainers at Padepokan Judo Ksatria Bhayangkara (PJKB). This training needs to be done because the training process is still minimal. Trainers have the obligation to provide training and make athletes excel, but there are still limitations in doing so. Training for novice athletes is still very much needed because of the lack of planning and maturity in carrying out training activities both in terms of training material and from the intensity given. Higher education as an institution that produces trainers and educators, as well as an organization that organizes community service activities, has a moral obligation to carry out coaching and training. For this reason, community service programs providing athlete training are the way to be taken to overcome this problem. Activities include physical condition training. The material discussed is the judo training program. The training is planned to be held on October to December 2020.
\end{abstract}

Keywords: Judo, Physical Condition, Training

\begin{abstract}
Abstrak
Tujuan kegiatan Pengabdian Kepada Masyarakat ini adalah memberikan pelatihan kondisi fisik kepada para atlet pemula, program latihan kepada para pelatih fisik di Padepokan Judo Ksatria Bhayangkara (PJKB). Pelatihan ini perlu dilakukan karena adanya proses latihan yang masih minim. Pelatih memiliki kewajiban untuk memberikan latihan dan menjadikan atlit berprestasi, namun masih ada keterbatasan dalam melaksanakannya. Pelatihan bagi atlet pemula masih sangat diperlukan karena kurangnya perencanaan dan kematangan dalam melakukan kegiatan latihan baik dari segi materi latihan maupun dari intensitas yang diberikan. Perguruan Tinggi sebagai lembaga penghasil pelatih maupun pendidik, sekaligus lembaga yang secara terorganisisir melaksanakan kegiatan pengabdian kepada masyarakat memiliki kewajiban moril untuk melakukan pembinaan dan pelatihan. Untuk itu program pengabdian kepada masyarakat menghadirkan untuk memberikan pelatihan atlet adalah cara yang ditempuh untuk mengatasi masalah tersebut. Kegiatan meliputi pelatihan kondisi fisik. Materi yang dibahas adalah program latihan judo. Pelatihan direncanakan akan dilaksanakan pada tanggal Oketober hingga Desember 2020.
\end{abstract}

Kata kunci: Judo, Kondisi fisik, Pelatihan

\section{Pendahuluan}

Tercapainya prestasi tinggi diperoleh melalui pembinaan yang tepat dan benar, serta usaha keras yang timbul dari diri seseorang pejudo (Buono et al., 2019). Selain itu perlu ditunjang oleh berbagai faktor, diantaranya kemampuan menguasai teknik-teknik kondisi fisik yang prima, sehingga mental, kualitas pelatih, didukung juga dengan sarana dan prasarana 
yang baik, serta disiplin ilmu yang erat tujuannya dengan olahraga, juga harus ditunjang dengan program latihan yang direncanakan sebaik-baiknya sehingga terarah dan bermutu (Kamadi, 2020).

Kegiatan pengabdian kepada masyarakat yang diusulkan adalah di PJKB DKI Jakarta yaitu tentang "Latihan Kondisi Fisik". Seperti dijelaskan (Lakicevic et al., 2020) yakni:" though you should be familiar with all kid of nage waza,you will find it to your advantage to discover the one or two that particuraly seem to suit yoi and work on them until you have mastered them completely", dan mengumpulkan satu atau dua teknik yang paling cocok baginya dan malakukan latihan sehingga benar-benar menguasainya (Roklicer et al., 2020). Oleh karena itu seorang pejudo harus menguasai teknik andalan dengan sebaik mungkin. Kondisi Fisik termasuk salah satu hal yang penting dalam melaksanakan latihan dan termasuk bagian dalam program latihan (Purnamasari \& Febrianty, 2020). Dalam pelaksanaan berlatih tentu ada suatu masalah yang hampir setiap cabang olahraga mengalami yaitu adanya latihan yang kurang baik (Muhtarifudin \& Soenyoto, 2020). Hal ini akan berakibat kepada prestasi atlet, sehingga ketika dipaksakan akan berakibat cidera pada atlet (Andriyono \& Soenyoto, 2020).

Dalam salah satu cabang olahraga yaitu cabang olahraga judo juga menemui permasalahan yang hampir sama bagi atlet pemula di PJKB DKI Jakarta. Dari hasil observasi yang telah ditemukan penulis pada Bulan Maret 2020 bahwa materi latihan yang masih minim, materi latihan yang sama dengan intensitas latihan yang kurang sesuai, kurangnya latihan yang diberikan pelatih, dan belum optimalnya mental atlet pemula di club tersebut, seringkali menjadi kelemahan dan bahkan judo di seluruh Indonesia. Sehingga sulit untuk mengoptimalkan prestasi judo, apabila hal itu tidak dilakukan evaluasi dan tidak dilakukan sosialisasi serta pelatihan langsung terhadap atlit pemula maka akan berdampak buruk pada prestasi dalam club tersebut. Oleh karena itu, pentingnya mengevaluasi materi latihan, program latihan agar bisa mencapai puncak prestasi di PJKB DKI Jakarta.

Selain itu kondisi fisik juga merupakan dasar untuk mengatur kesiapan atlit pemula dalam berlatih dan bertanding agar atlit bisa memberikan kekuatan fisik yang maksimal dan menghasilkan atlit yang berprestasi sesuai dengan yang diharapkan para pelatih dan pengurus club (Safitri \& Jannah, 2020). Untuk itu dengan diberikan pelatihan tersebut akan berdampak baik terhadap hasil yang akan dicapai.

PJKB DKI Jakarta adalah merupakan salah satu Padepokan judo ksatria bhayangkara klub judo Jakarta berlokasi di Jl. Ciputat Raya No. 40 Pondok Pinang, Kebayoran Lama, Jakarta Selatan. Didirikan di bawah naungan Pengurus Provinsi Persatuan Judo Seluruh Indonesia DKI Jakarta pada tahun 1991. Merupakan salah satu klub tertua yang mempunyai sejarah panjang di Indonesia. Saat ini PJKB judo sudah terdaftar sebagai klub olahraga yang berbadan hukum dan menjadi klub yang melakukan pembinaan judo yang profesional sehingga mampu menciptakan atlet-atlet judo berprestasi yang mampu membawa Indonesia sampai kancah Internasional. PJKB ini adalah salah satu mitra Ubhara Jaya untuk membentuk suatu kualitas mahasiswa melalui latihan dan bimbingan pelatih dari atlit pemula sampai atlit senior dengan 
tujuan menjadikan prestasi sebagai ujung puncak karir atlit. Hal tersebut sejalan dengan yang diamanatkan dalam (UU No 3 Tahun 2005, 2005) bahwa, "olahraga adalah segala kegiatan yang sistematis untuk mendorong, membina, serta mengembangkan potensi jasmani, rohani, dan sosial" dan undang-undang republik Indonesia No.9 tahun 1995 tentang kemitraan adalah kerjasama usaha antara usaha kecil dan usaha menengah atau usaha besar disertai pembinaan dan pengembangan oleh usaha menengah atau usaha besar dengan memperhatikan prinsip saling memerlukan, saling memerlukan, saling memperkuat dan saling menguntungkan.

Dengan demikian dapat disimpulkan bahwa perlunya Program Studi Pendidikan Kepelatihan Olahraga FIP Universitas Bhayangkara Jakarta Raya memeliki mitra yang selaras untuk mengembangkan keterampilan mahasiswa dan Stakeholder untuk mencapai tujuan yang sama dan lebih efektif. Oleh karenanya penulis memperbaiki latihan fisik atlet agar mencapai harapan dan tujuan yang dikehendaki sehingga luaran dalam kegiatan pengabdian ini diharapkan menjadi lebih baik lagi.

Berdasarkan dari beberapa hasil penelitian terkait pengabdian kepada masyarakat dengan ditemukannya beberapa judul yang sesuai dengan abdimas ini yaitu kondisi fisik atlit pencak silat oleh (Susanto et al., 2020) yang dimana mencari tahu level kondisi fisik atlit pencak silat dipadepokan tangan mas kabupaten agam. Adapun penelitian tentang tingkat kondisi fisik atlet pencak silat psht di padepokan PSHT kabupaten tulung agung yang dilakukan oleh (Rahayu, 2018) dimana Penelitian ini dilatar belakangi oleh hasil pengamatan dan pengalaman peneliti di padepokan PSHT kabupaten Tulungagung bahwa adanya fakta belum diketahuinya kondisi fisik atlet pencak silat dan program latihan kondisi fisik belum direncanakan secara baik dan sistemati. Penelitian dewi nurhidayah tentang profil kondisi fisik atlet unit kegiatan mahasiswa pencak silat universitas negeri yogyakarta kategori tanding pada putra dan putri, yang dimana Penelitian ini bertujuan untuk mengetahui profil kondisi fisik atlet UKM Pencak Silat UNY kategori tanding pada putra dan putri.

\section{Metode Pelaksanaan}

Kegiatan Pengabdian Kepada Masyarakat di PJKB DKI Jakarta ini mulai dari Bulan Oktober sampai dengan Desember tahun 2020. Metode yang digunakan dalam kegiatan ini adalah berupa pelatihan yang berisi ceramah penyampaian materi fisik, diskusi, dan praktek. Pendekatan ceramah dan diskusi ini diharapkan mampu memberikan pemahaman konsep dan menggali secara mendalam masalah-masalah yang ada di lapangan demikian juga solusi yang akan ditawarkan secara langsung sesuai dengan harapan bersama. Bersamaan yang dikatakan oleh (Harsono, 2013) tentang program latihan yaitu sasaran akhir dari program latihan adalah untuk mencapai kondisi fisik puncak agar prestasi maksimal dapat tercapai pada masa roda kompetisi yang paling penting berlangsung. Kegiatan pemberian materi diberikan berlangsung selama kurang lebih 45 menit dan diakhir sesi diberikan kesempatan kepada peserta untuk mengajukan pertanyaan terkait materi yang telah disampaikan. 
Kegiatan Pengabdian Masyarakat ini dilakukan melalui langkah-langkah diantaranya kegiatan persiapan, kegiatan pelatihan dan penutup.

Dari kegiatan persiapan hal-hal yang dilakukan diantaranya a) Persiapan kegiatan meliputi: kegiatan survey tempat pengabdian masyarakat yaitu: di PJKB DKI Jakarta Jl. Indonesian Police Woman Academy (SEPOLWAN, RT.10/RW.9, Pd. Pinang, Kec. Kby. Lama, Kota Jakarta Selatan, Daerah Khusus Ibukota Jakarta 12310; b) Permohonan izin kepada pengurus Club PJKB; c) Pengurusan administrasi surat menyurat; d) Persiapan alat dan bahan serta akomodasi; e) Persiapan untuk pelatihan dilapangan

Hal- hal yang dilakukan pada kegiatan pelatihan, diantaranya a) Pembukaan dan perkenalan kepada atlit pemula dan pelatih; b) Memberikan teori tentang kondisi fisik judo; c) Memberikan masukan kepada pelatih tentang program Latihan; d) Sesi diskusi Tanya jawab perihal pelatihan kondisi fisik; e) Evaluasi latihan dan lain-lain.

Penutupan kegiatan pelatihan ini dilakukan kegiatan foto bersama antara panitia dan peserta melalui aplikasi zoom, berpamitan dengan pengurus serta para pelatih dan atlit dan pembuatan laporan pengabdian kepada masyarakat.
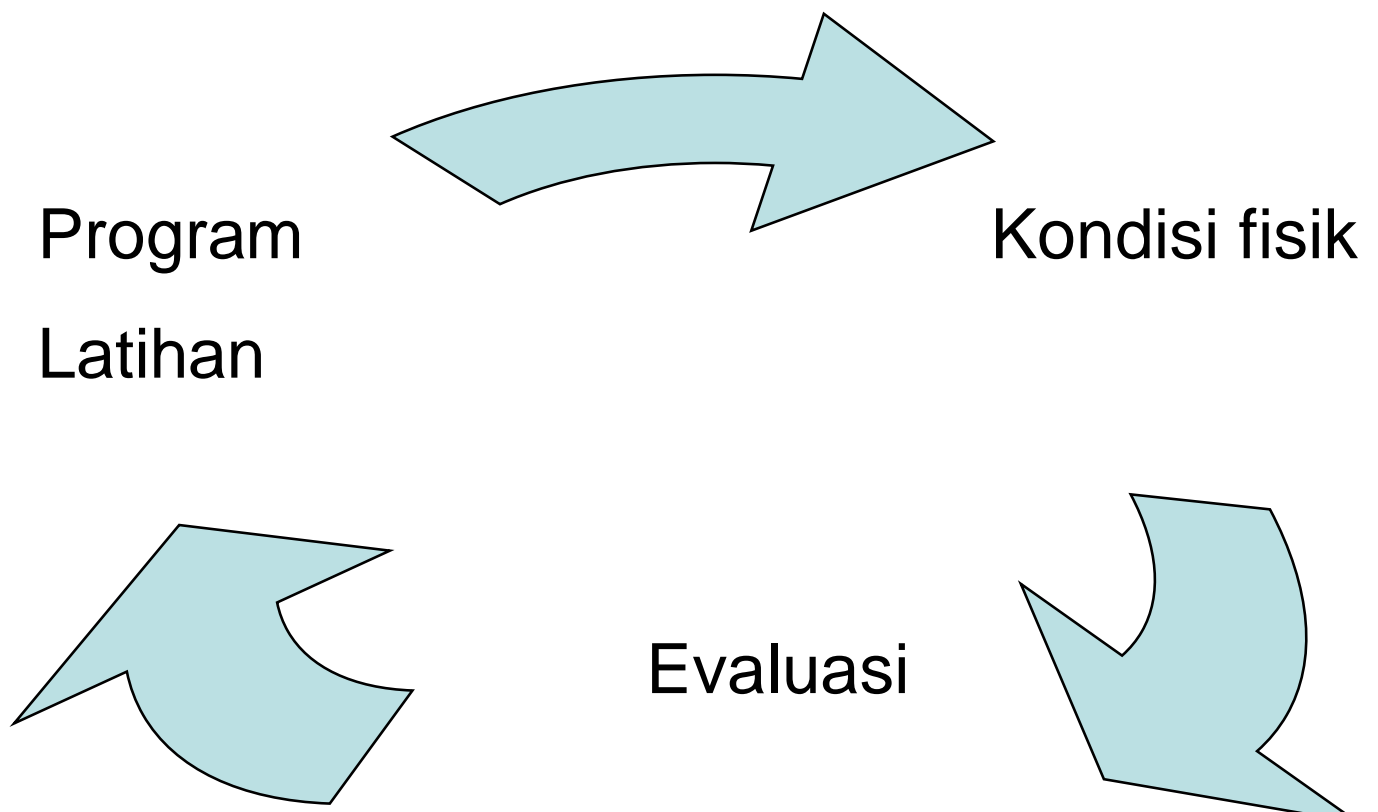

\section{Evaluasi}

Sumber: Hasil Pelaksanaan (2021)

Gambar 1. Tahapan Kegiatan Pelatihan

\section{Hasil dan Pembahasan}

\subsection{Hasil}

Secara umum kegiatan pengabdian masyarakat ini berjalan dengan lancar. Pengurus dan pelatih membantu mempersiapkan tempat dan alat-alat yang dipakai serta mengakomodir peserta yang dimana peserta merupakan atlit pemula di PJKB DKI Jakarta. 


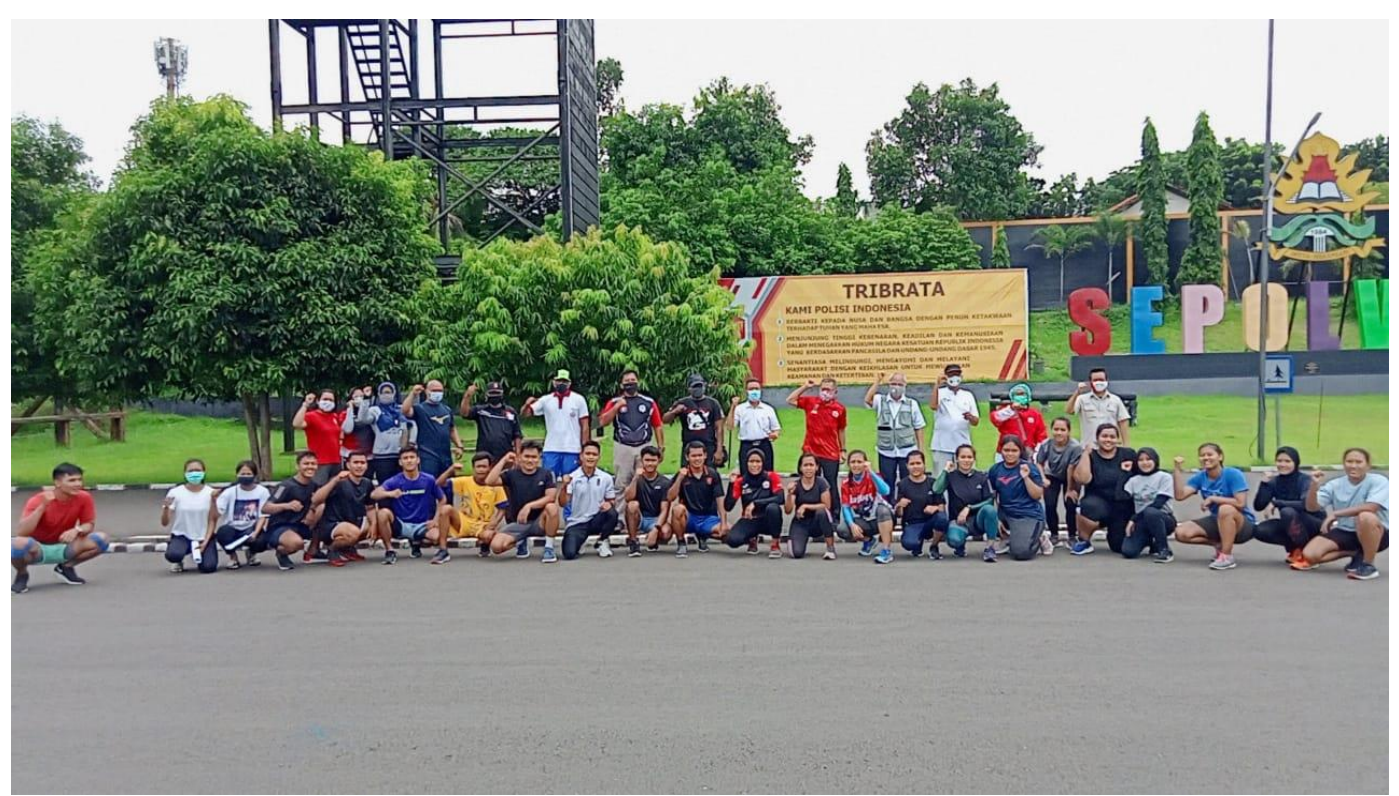

Sumber: Hasil Pelaksanaan (2021)

Gambar 2. Sesi Foto Bersama Pelaksanaan Abdimas

Kegiatan dilakukan dengan metode pelatihan yang berisi ceramah penyampaian materi fisik, diskusi, dan praktek. Kegiatan ini dilakukan setiap hari Sabtu selama bulan Oktober Desember 2020. Peserta berjumlah 15 orang sebagai atlit pemula di club tersebut. Pelaksanaan PKM dilaksanakan dua orang dengan pokok bahasan yang disampaikan mengenai kondisi fisik untuk atlit dan program latihan untuk pelatih, selanjutnya evaluasi.

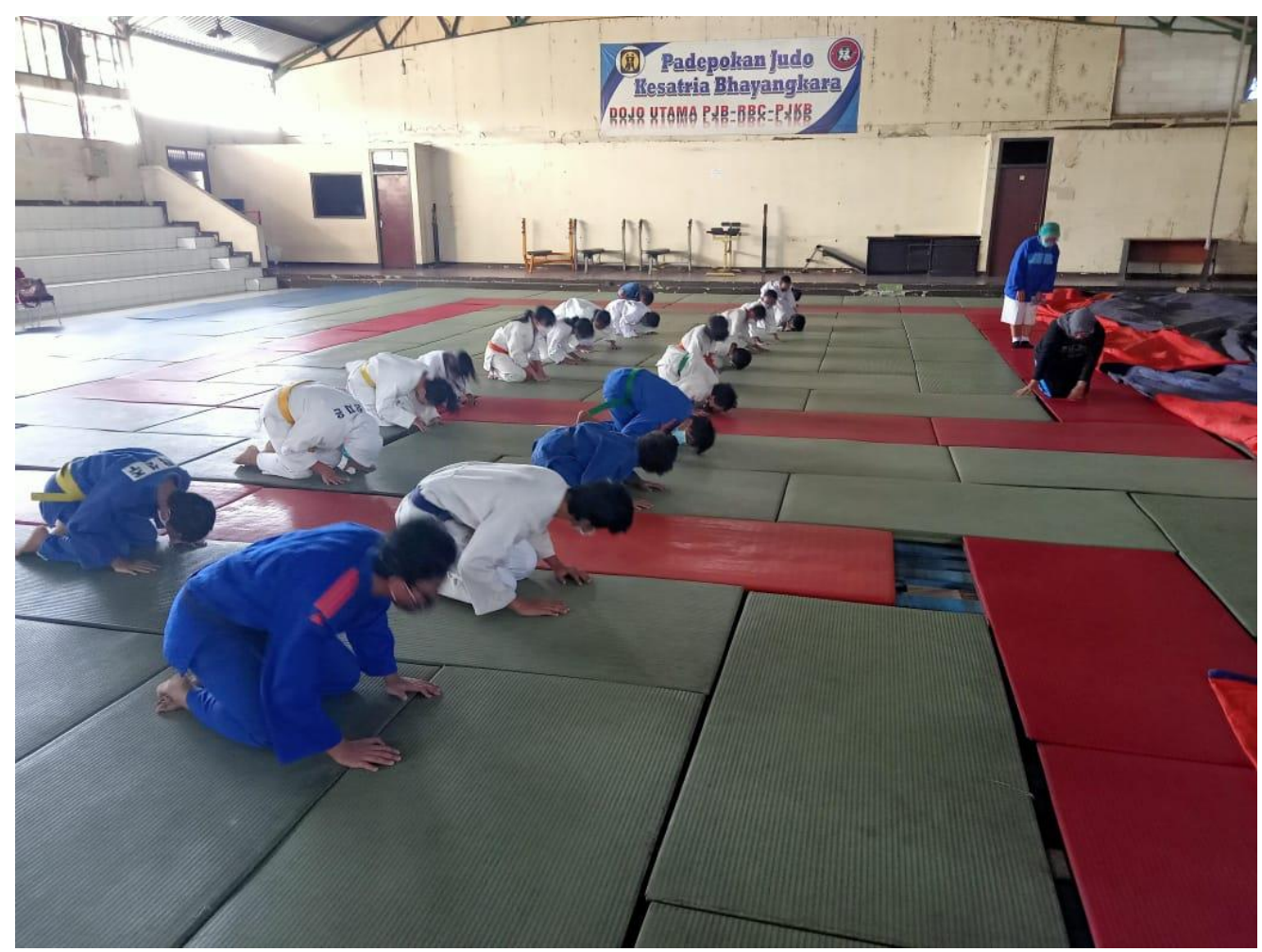

Sumber: Hasil Pelaksanaan (2021)

Gambar 3. Pelaksanaan Pelatihan Abdimas 
Kegiatan yang diawali dengan ceramah kemudian dilanjutkan diskusi lalu praktek, dari kegiatan diskusi dan praktek tampak bahwa atlit dan pelatih belum begitu memahami cara membuat program latihan dan latihan kondisi apa yang sesuai dengan kebutuhan mereka. Acara kemudian dilanjutkan dengan evaluasi program latihan dan latihan kondisi fisik sampai mereka benar-benar memahami apa yang diberikan materinya oleh para pengabdi.

Secara garis besar beberapa keberhasilan pengabdian kepada masyarakat yaitu: a) Keberhasilan harapan pengabdi kepada atlit dan pelatih; b) Keberhasilan target materi yang telah diberikan; c) Kemampuan peserta dalam menguasai materi; d) Kesesuaiannya waktu yang dibutuhkan.

Ada pun kendala yang ditemui selama proses kegiatan pengabdian kepada masyarakat adalah ketidak hadiran para peserta, sehingga perlu adanya informasi dan motivasi terhadap para atlit pemula yang ada di club tersebut untuk bisa mengikuti pelatihan pengabdian kepada masyarakat.

Materi kondisi fisik dan program Latihan. Menyatakan bahwa strength, speed dan endurance adalah Varietas jenis pelatihan, pelatihan dan program yang berbeda agar tidak membosankan. Individualisasi, programnya tidak selalu sama dengan atlet lain. Latihan keras, menyatakan agar ada latihan pemulihan, semakin besar intensitas pelatihan semakin lama pemulihan yang dibutuhkan pelatihan. Multilateral, untuk semua bidang peningkatan fisik. Reversibilitas, dari dasar hingga spesialisasi. Jenis program pelatihan seperti untuk latihan beban, Total semua waktu pelatihan, kualitasi komponen serta pelatihan.
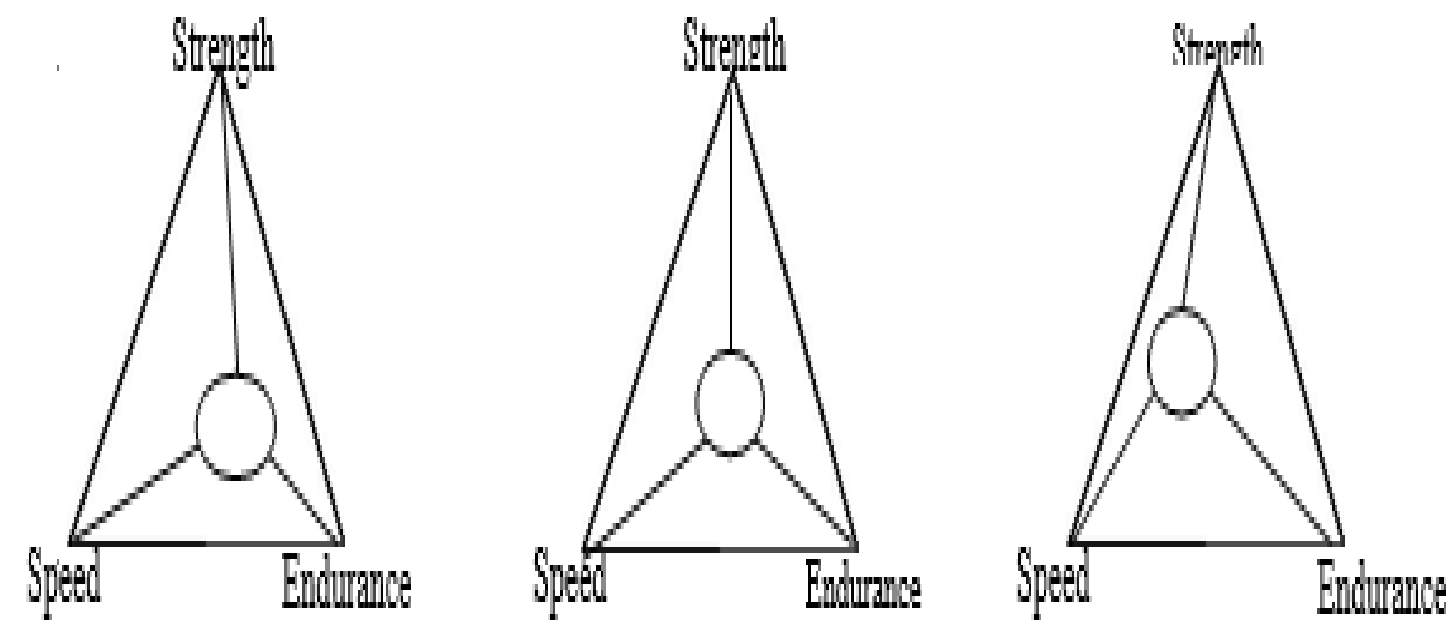

Sumber: ASCA LEVEL 1

Gambar 4. Dominan endurance, Dominan Speed dan Dominan Strength

Berikut pemaparan mengenai program latihan yang dilakukan pada kegiatan pelaksanaan pengabdian kepada masyarakat dalam bentuk tabel. 
Tabel 1. Program Latihan ABDIMAS

\begin{tabular}{|c|c|c|c|c|c|c|}
\hline Day of Week & $\mathrm{Am} / \mathrm{Pm}$ & Type & RPE & Duration & = Unit Load & Daily Load \\
\hline Sunday & $07.00-08.00$ & STR & 2 & 60 Minute & 120 & 120 \\
\hline \multirow{2}{*}{ Monday } & $07.00-08.00$ & FLEX & 2 & 60 Minute & 120 & 120 \\
\hline & $16.00-17.00$ & SPEED & 2 & 60 Minute & 120 & 120 \\
\hline Tuesday & $16.00-17.00$ & REC ACTIVE & 2 & 60 Minute & 120 & 120 \\
\hline Wednesday & $07.00-08.00$ & STR & 3 & 60 Minute & 180 & 180 \\
\hline Thursday & $08.00-09.00$ & REC & 3 & 60 Minute & 180 & 180 \\
\hline Friday & $09.00-10.00$ & SPEED & 4 & 60 Minute & 240 & 240 \\
\hline \multicolumn{7}{|l|}{ Saturday } \\
\hline & & & & & \multicolumn{2}{|c|}{ WEEKLY } \\
\hline
\end{tabular}

Sumber: Hasil Pelaksanaan (2021)

Pelatihan yang telah kembangkan, dengan teoritis dan waktu/durasi untuk durasi sesi. Menunjukkan skor total untuk setiap sesi dicapai dan kemudian menunjukkan ketercapaian latihan selama perminggu. Perbedaan yang jelas antara minggu berat dengan minggu beban kerja mudah/ringan.

\subsection{Pembahasan}

Berdasarkan tabel 1 dapat dijelaskan bahwa, kegiatan pelaksanaan pengabdian ini dilakukan setiap hari dengan rentang waktu dari pukul 07.00-10.00 WIB. perlakuan yang diberikan setiap harinya berbeda berdasarkan tingkatan, untuk itu diperlukan kondisi fisik yang baik bagi para atlet agar setiap tingkatan dapat dilakukan dengan benar. Kondisi fisik sangat diperlukan bagi setiap atlet untuk mengoptimalkan teknik dalam setiap gerakan (Ridwan M \& Irawan $R, 2018$ ). Hal senada juga disampaikan oleh (Saputra \& Aziz, 2020) yang menyatakan bahwa kondisi fisik salah satu dasar yang sangat penting dalam setiap cabang olahraga dalam meningkatkan prestasi. Dapat disimpulkan bahwa kondisi fisik merupakan suatu prosedur dasar yang harus dimiliki oleh seorang atlet dalam melakukan setiap gerakan ataupun teknik, sehingga setiap gerakan dapat dilakukan dengan benar.

Untuk cabang olahraga judo, kondisi fisik sangat diperlukan untuk dapat melakukan teknik latihan seperti tendoku reshu, tachi waza, newaza, dan ukemi dan lain sebagainya (Purnamasari \& Febrianty, 2020). Ketika atlet memiliki kondisi fisik yang baik, tentu akan dapat melakukan semua teknik judo dengan baik. Seperti yang diketahui, judo merupakan salah satu cabang olahraga yang membutuhkan kondisi fisik yang baik untuk dapat melawan musuh dalam gerakan membanting ke udara untuk mempertahankan diri (Safitri \& Jannah, 2020). Kedua pernyataan tersebut diperkuat oleh (Jariono et al., 2020) yang menyatakan bahwa kondisi fisik merupakan rangkaian gerakan yang dilakukan secara sengaja untuk meningkatkan kebugaran serta kesehatan jasmani. Artinya kondisi fisik berasal dari diri seorang atlet yang berkeinginan untuk memperkuat ataupun meningkatkan kebugaran tubuh agar data melakukan serangkaian gerakan-gerakan ataupun teknik dalam olahraga judo. 
Berdasarkan fakta observasi yang telah dikemukakan di latar belakang, pengabdian kepada masyarakat tetap dilaksanakan secara online. Hasil dari kegiatan pengabdian ini ditemukan beberapa capaian seperti para atlet dapat menerima seluruh materi yang diberikan, kemampuan para atlet dalam melakukan teknik olahraga judo sangat baik. Namun, terdapat kendala saat proses pengabdian ini berjalan, terdapat beberapa atlet yang terlambat hadir. Untuk itu, para peneliti telah berkomunikasi dengan para pelatih untuk dapat memotivasi para atlet agar meningkatkan kedisiplinan dan terus berinovasi dalam meningkatkan dan mengembangkan prestasi atlet. Dengan adanya pengabdian secara online ini, diharapkan kepada pelatih serta atlet agar terus berinovasi dengan memanfaatkan teknologi dalam membuat program latihan.

\section{Kesimpulan}

Setelah melaksanakan kegiatan pengabdian kepada masyarakat ini dengan judul "Pelatihan Kondisi fisik atlit padepokan judo kesatria Bhayangkara (PJKB) DKI Jakarta". Kedepan, pengabdian kepada masyarakat akan terus dilakukan agar hasil dari kegiatan ini menjadi berkembang dan menjadi lebih baik, utamanya bagi para atlet yang telah diberikan materi latihan fisik, program latihan sehingga dapat memberikan kontribusi yang lebih nyata. Berharap, dengan diadakan kegiatan pengabdian kepada masyarakat ini akan menjadikan barometer khusus untuk latihan fisik, program latihan pada club-club pelatihan judo diseluruh Indonesia. Fakultas IImu Pendidikan Universitas Bhayangkara Jakarta Raya khususnya Program Studi Pendidikan Kepelatihan Olahraga berharap hasil dari kegiatan ini dapat menjadikan calon - calon atlet berprestasi yang dapat mengharumkan nama perguruan tinggi, club serta bangsa dan Negara. Berdasarkan hasil evaluasi respon yang telah dilakukan dilapangan, hendaknya program-program pengabdian kepada masyarakat ini dilaksanakan secara berlanjut dan terus menerus, melihat tingkat kebutuhan para atlet, pelatih, agar latihan tidak sia-sia dan prestasi dan bibit selalu muncul begitu juga untuk kebanggaan. Kemudian para pelatih dan Dosen Pendidikan Kepelatihan Olahraga FIP Ubhara Jaya dapat terus memberikan dorongan, solusi dalam menyelesaikan persoalan yang terjadi club dan masyarakat, sehingga muncul terobosan dan gagasan baru dalam konsep program latihan yang lebih baik lagi dalam peningkatan proses belajar menggajar dan juga proses pelatihan.

\section{UCAPAN TERIMA KASIH}

Puji dan syukur penulis panjatkan kepada Allah SWT, Tuhan Yang Maha Kuasa atas segala rahmat dan kasih karunia-Nya yang memberikan kesehatan dan kesempatan pada penulis sehingga Pengabdian Kepada Masyarakat ini dapat diselesaikan dengan baik. Dalam menyelesaikan Pengabdian Kepada Masyarakat ini banyak kendala yang dihadapi penulis dan dapat diselesaikan berkat bimbingan dan dorongan dari berbagai pihak yang akhirnya penulisan ini dapat diselesaikan sebagaimana mestinya. Pada kesempatan ini penulis menyampaikan ucapan terima kasih kepada: a) Pimpinan Universitas Bhayangkara Jakarta 
Raya yang telah memberikan materi maupun moril dari hibah internal kampus hingga pengabdian ini selesai dilaksanakan; b) Pimpinan dan pengurus PJKB di Jakarta sebagai penasehat sekaligus menyusun administrasi surat menyurat penulis; c) Para Pelatih di PJKB sebagai peserta sekaligus yang membantu terlaksananya pengabdian kepada masyarakat; d) Lembaga Penelitian dan Pengabdian Masyarakat Universitas Bhayangkara Jakarta Raya sebagai perpanjangan kampus pemberi hibah internal; e) Dan buat pihak yang telah banyak membantu menyelesaikan pengabdian ini, pengabdi mengucapkan terima kasih yang tak terhingga. Akhirnya, pengabdi berharap semoga pengabdian kepada masyarakat ini dapat bermanfaat bagi semua dan menjadi bahan masukan bagi pengembang dunia pendidikan dan kepelatihan khususnya olahraga judo didaerah DKI Jakarta.

\section{DAFTAR PUSTAKA}

Andriyono, M. J., \& Soenyoto, T. (2020). Penelusuran Minat dan Bakat Olahraga pada Siswa Sekolah Menengah Pertama di Kabupaten Jepara. Indonesian Journal of Physical $\begin{array}{llll}\text { Education } \quad \text { and } & \text { Sport, }\end{array}$ https://doi.org/https://doi.org/10.15294/inapes.v1i2.39813

Buono, H., Maulina, P., \& Muzakkir. (2019). Analisis Framing terhadap Pemberitaan Didiskualifikasinya Miftahul Jannah Dari Cabang Olahraga Judo. Jurnal IImu Komunikasi, 5(2), 1689-1699. https://doi.org/10.35308/source.v5i2.1398

Harsono. (2013). Coaching dan Aspek-Aspek Psikologi dalam Coaching. Dedikbud Dirjen Dikti. Jariono, G., Nursubekti, N., Indarto, P., Hendarto, S., Nugroho, H., \& Fachrezy, F. (2020). Analisis kondisi fisik menggunakan software Kinovea pada atlet taekwondo Dojang Mahameru Surakarta. Transformasi: Jurnal Pengabdian Masyarakat, 16(2), 133-144. https://doi.org/10.20414/transformasi.v16i2.2635

Kamadi, L. (2020). Kontribusi Kondisi Fisik Terhadap Kemampuan Servis Bawah Dalam Permainan Bolavoli Contribution of Physical Conditions to Lower Service Ability in Volleyball Games. Journal Coaching Education Sports, 1(2), 151-160. https://doi.org/https://doi.org/10.31599/jces.v1i2.369

Lakicevic, N., Roklicer, R., Bianco, A., Mani, D., Paoli, A., Trivic, T., Ostojic, S. M., Milovancev, A., Maksimovic, N., \& Drid, P. (2020). Effects of rapid weight loss on judo athletes: A systematic review. Nutrients, 12(5). https://doi.org/10.3390/nu12051220

Muhtarifudin, R., \& Soenyoto, T. (2020). Penelusuran Minat dan Bakat Olahraga Pada Siswa Sekolah Menengah Pertama di Kabupaten Demak. Indonesian Journal of Physical Education and Sport, $\quad 1(1), \quad 98-104$. https://doi.org/https://doi.org/10.15294/inapes.v1i2.40538

Purnamasari, I., \& Febrianty, M. F. (2020). Adaptasi Latihan Judo Di Masa Pandemi Covid-19. Jurnal Penjakora, 7(2), 151-159. https://doi.org/10.23887/penjakora.v7i2.27544 Article Metrics

Rahayu, N. (2018). Tingkat Kondisi Fisik Atlet Pencak Silat di Padepokan PSHT Kabupaten 
Tulungagung Tahun 2017. Jurnal Simki Techsain, 02(05), 1-12. http://simki.unpkediri.ac.id/detail/13.1.01.09.0248

Ridwan M \& Irawan R. (2018). Kondisi Fisik Pemain Sekolah Sepakbola (SSB) Kota Padang. Jurnal Performa Olahraga, 5(2018), 65-72. https://doi.org/https://doi.org/10.24036/jpo142019

Roklicer, R., Lakicevic, N., Stajer, V., Trivic, T., Bianco, A., Mani, D., Milosevic, Z., Maksimovic, N., Paoli, A., \& Drid, P. (2020). The effects of rapid weight loss on skeletal muscle in judo athletes. Journal of Translational Medicine, 18(1), 1-7. https://doi.org/10.1186/s12967020-02315-x

Safitri, A., \& Jannah, M. (2020). Hubungan antara Regulasi Emosi dengan Kecemasan Olahraga pada Atlet Judo. Jurnal Penelitian Psikologi, 07(1989), 51-58. https://jurnalmahasiswa.unesa.ac.id/index.php/character/article/view/34497/30678

Saputra, N., \& Aziz, I. (2020). Tinjauan Tingkat Kondisi Fisik Pemain Bolavoli Putra Sma 2 Pariaman. Performa Olahraga, 5(1), 39-47. https://doi.org/https://doi.org/10.24036/jpo137019

Susanto, D. M., Maidarman, Suwirman, \& Lesmana, H. S. (2020). Kondisi Fisik Atlet Pencak Silat. Jurnal Patriot, 2(3), 692-704. https://doi.org/10.4135/9780857020116.n162

UU No 3 Tahun 2005. (2005). Undang-Undang Republik Indonesia Nomor 3 Tahun 2005 Tentang Sistem Keolahragaan Nasional Dengan. In Presiden RI. 